\title{
Ulaşım Güvenliğini Sağlamada Bir Araç Olarak Planlama
}

\author{
* \\ İrem Ayhan Selçuk \\ Dokuz Eylül Üniversitesi
}

\begin{abstract}
Öz
Ulaşım güvenliği, kent güvenliğinin önemli bir parçasını oluşturmaktadır. Çünkü ulaşım hatları, ayn zamanda güvensiz unsurlarm belli bir noktadan diğerine taşınmasına neden olabilecek mekânsal unsurlardır. Planlama mevzuatı ulaşım güvenliği konusunda doğrudan araç tarifinde bulunmasa da; mekânsal planlar yapım yönetmeliğinde ulaşım güvenliğinin să̆lanmasında araç olarak kullanılabilecek çok sayıda değiş̧ken bulunmaktadır. Dolayısıyla özellikle şehir plancılara, ulaşım güvenliğini sağlamada büyük bir rol düşmektedir. Bu çalışmanın amaci; ulaşım güvenliğini sağlamaya yönelik olarak kullanılabilecek mevcut ya da öneri planlama aracı önerilerinde bulunarak; araştırmacıları bu araçları test edebilecekleri bilimsel çalışmalar gerçekleştirmeleri için teşvik etmektir. Bunun sonucunda ulaşım açısından daha güvenli ve dolayısılyla daha yaşanabilir çevreler oluşturulmuş olacaktır. Kent güvenliğini oluşturan bileşenlerden biri olan ulaşım ve trafik güvenliğine ilişkin kullanılabilecek mekânsal planlama araçları ise bu çalışmanın kapsamını oluşturmaktadır. Çalışma kapsamında öncelikle literatürde ulaşım ve trafik güvenliğinin ele alınış biçimi ortaya koyulacak; şehir planlama disiplininin hangi araçları kullanarak trafik problemlerine çözüm bulabileceği konusunda öneriler gerçekleştirilecektir. Çalışma trafikte karşılaşılan problemler üzerinden; bu problemlerin çözümünde kullanılabilecek planlama araçlarını sorgulayan bir yönteme sahiptir. Kentsel mekanın tasarımında rol alacak ya da mekanın tasarımına etkisi olacak tüm meslek alanlarının tasarım ya da planlama çalışmaların gerçekleştirirken ulaşım güvenliğini tehlikeye atacak uygulamalardan kaçınmaları gerekmektedir. Bu çalışma söz konusu meslek alanlarından şehir plancılarına odaklanmakta olup; ulaşım güvenliğinin sağlanmasında kullanılabilecek planlama araçları öneriyor ve tartışmaya açıyor olması; çalışmanın özgünlü̆̆̈̈̈nü ve bilime katkısını oluşturmaktadır.
\end{abstract}

Anahtar Kelimeler: Güvenlik, Kent, Ulaşım, Ulaşım Güvenliği, Trafik Güvenliği, Arazi Kullanım, Planlama Araçları 


\title{
Planning as a Tool for Providing Transportation Safety \\ *
}

\author{
İrem Ayhan Selçuk \\ Dokuz Eylül Üniversitesi
}

\begin{abstract}
Transportation security is an important part of urban security. Because transport lines are spatial elements that can cause insecure elements to move from one point to another. Although the planning legislation is not directly in terms of transportation security, there are several variables that can be used as a tool for securing the transportation safety in spatial planning construction regulations. Therefore, urban planners play a crucial role in securing transportation security. The purpose of this study is; proposing an existing or proposal planning tool that can be used to provide transportation security; researchers are encouraging these tools to perform scientific work that they can. As a result, safer and therefore more livable environments will be created in terms of transportation. The spatial planning tools that can be used for transportation and traffic safety, which are components of urban security, constitute the scope of this study. Within the scope of the study, firstly, the way of handling transportation and traffic safety will be explained in the literature; suggestions will be made about which means of urban planning discipline can solve traffic. This work; focuses on the city planners from the profession areas in question; proposes and debates planning tools that can be used to ensure transportation safety; the nature of work and the contribution of the science.
\end{abstract}

Keywords: Security, City, Transportation, Transportation Security, Traffic Security, Land Use, Planning Tools 


\section{Giriş}

Kent; çok katmanlı bir yapı olup; içerisinde barındırdığı farklı arazi kullanım türleri, yapı ve nüfus yoğunlukları, tarihsel katmanları, ulaşım ve altyapı elemanları ile farklı demografik, sosyal ve kültürel özelliklere sahip insanları biraraya getiren ve dolayısıyla iletişim kanallarını kuvvetlendiren ve kültürler ve çağlar arası bilgi aktarımı sağlanmasına yardımcı olan bir zemindir.

Bu kadar çok farklılığın birarada olması; kentte çok çeşitli uyumsuzlukların ortaya çıkmasına neden olmaktadır. Bu uyumsuzlukları minimize etme görevi ise daha çok yerel yönetimlere ve yerel yönetimlerin desteğini alarak birarada çalışan uzmanlık alanlarına düşmektedir. Yerel yönetimlerin başarısı ise; kent halkını ve kentsel mekanı iyi tanımalarına ve dolayısıyla doğru çözümler bulmalarına bağlıdır.

Pek çok farklılı̆̆ın birarada olduğu kentlerde; insanların güven içinde yaşaması büyük öneme sahiptir. Kuramsal açıdan incelendiğinde suça neden olan faktörler ekonomik, sosyal, kültürel, demografik ve mekânsal faktörler olmak üzere beş kategoride incelenmektedir. Suçun mekânsal belirleyicileri ise planlama araçlarını kullanarak suçu azaltıı önlemlerin alınabileceği bir faktörler grubunu oluşturmaktadır. İnsanların güvenliğini tehdit altına alan suç kategorileri adam öldürme, hırsızlık, darp, yaralama, kapkaç, yankesicilik, vandalizm, tecavüz vb. olup; trafik suçları da kent güvenliğinin önemli bir parçasını oluşturan ulaşım güvenliğinin sağlanmasında ayrı bir kategori oluşturmaktadır.

Literatürde ulaşım güvenliği denilince iki konu üzerine özellikle odaklanıldığı gözlemlenmiştir. Bunlardan birincisi trafik kazaları nedeniyle oluşan güvenlik problemleri, ikincisi terör olayları nedeniyle oluşan güvenlik problemleridir. Bu çalışmanın odaklandığı konu ise trafik kazaları nedeniyle oluşan güvenlik problemleridir.

Trafik kazaları daha çok insanların dikkatsizliği vb. temelli ortaya çkan unsurlar olsa da; taşıtların ya da yayaların üzerinde seyahat ettiği mekanlar; sahip oldukları özellikler nedeniyle trafik suçlarının oluşumunda büyük pay sahibi olabilmektedir. Mekanda reklam panoları gibi dikkat dağıtıcı unsurların çokluğu, görüş açısını daraltan, engelleyen ya da kör noktalar oluşturan mekânsal tasarımların varlığı, trafik yoğunluğunu arttıran okul, hastane vb. arazi kullanım türlerinin biraradalığı, yüksek yoğunluklu yapılara hizmet eden yetersiz genişlikte yollar, öngörülememiş ya da planlanamamış araç sayısına bağlı şerit ihlali ile sonuçlanan araç 
parklanmaları vb. pek çok faktör; kentte kaza oluşumunu arttırıcı etkide bulunarak ulaşım güvenliğini tehdit altına alabilir.

Dolayısıyla kentsel mekanın tasarımında rol alacak ya da mekanın tasarımına etkisi olacak tüm meslek alanlarının tasarım ya da planlama çalışmalarını gerçekleştirirken bu durumu da dikkate alarak; ulaşım güvenliğini tehlikeye atacak uygulamalardan kaçınmaları gerekmektedir. Bu çalışma sözkonusu meslek alanlarından şehir plancılarına odaklanmakta olup; ulaşım güvenliğinin sağlanmasında kullanılabilecek planlama araçları öneriyor ve tartışmaya açıyor olması; bu çalışmanın özgünlügünü ve bilime katkısını oluşturmaktadır.

\section{Araştırma Problemi}

Adam öldürme, kap kaç, yankesicilik, vandalizm, darp, yaralama, tecavüz vb. suç kategorileri daha çok kasıtlı olarak gerçekleştirilen ve altında başka sosyolojik ya da psikolojik nedenler olan suçlardır. Trafik kazaları ise daha çok kasıtsız ya da dikkatsizlik sonucu gerçekleşmesi ve mekâna bağlı uygulamalarla önlenebilecek ya da azaltılabilecek bir suç kategorisi olması nedeniyle diğer suçlardan farklı değerlendirilmelidir.

Trafik kazalarının azaltılmasına yönelik uygulamalarda "şehir planlama çalışmaları" etkin olarak kullanılabilecek bir araçtır. Yönetim kademelerinin desteğiyle birlikte "şehir planlama" gerekirse bir kente, kentsel bölgeye ya da kentin herhangi bir arterine girebilecek araç türüne, kentin o bölgesine ilişkin verdiği mekânsal kararlarla yön verme gücüne sahiptir. Dolayısıyla trafik suçları bu özelliğiyle diğer suçlardan farklılaşmakta olup; çözümü için mekânsal planlama; bir araç olarak kullanılabilir.

Ulaşım ya da trafik güvenliğini sağlayabilecek mekânsal planlama araçlarıyla ilgili yeterli analiz ve sentez çalışmalarının yapılmıyor ve plan kararlarına yansıtılmıyor olması; kent güvenliği açısından büyük bir eksiklik olup; bu çalışmanın problemini oluşturmaktadır.

\section{Araştırma Amaç ve Kapsamı}

Bu çalışmanın amacl; ulaşım güvenliğini sağlamaya yönelik olarak kullanılabilecek mevcut ya da öneri planlama aracı önerilerinde bulunarak; araştırmacıları bu araçları test edebilecekleri bilimsel çalışmalar gerçekleştirmeleri için teşvik etmektir. Bunun sonucunda ulaşım açısından daha güvenli ve dolayısıyla daha yaşanabilir çevreler oluşturulmuş olacaktır. 
Kent güvenliğini oluşturan bileşenlerden biri olan ulaşım ve trafik güvenliğine ilişkin kullanılabilecek mekânsal planlama araçları ise bu çalışmanın kapsamını oluşturmaktadır.

\section{Araştırma Yöntemi}

Çalışma kapsamında öncelikle literatürde ulaşım ve trafik güvenliğinin ele alınış biçimi ortaya koyulacak; şehir planlama disiplininin hangi araçları kullanarak trafik problemlerine çözüm bulabileceği konusunda öneriler gerçekleştirilecektir. Çalışma trafikte karşılaşılan problemler üzerinden; bu problemlerin çözümünde kullanılabilecek planlama araçlarını sorgulayan bir yönteme sahiptir.

\section{Kuramsal Çerçeve}

Çalışmanın bu bölümünde genel olarak literatürde ulaşım güvenliği kapsamında araştırmacıların odaklandıkları konular ortaya koyulmaya çalışılacaktır. Literatür taramaları; trafik kazalarının azaltılmasında ve ulaşım güvenliğinin sağlanmasında kullanılabilecek planlama araçları konusunda fikir vermesi açısından ve bugüne kadar test edilip ispatlanmış mekânsal araçları görmek açısından büyük önem taşımaktadır.

Polzin (b.t.), ulaşımın güvenliğe ihtiyaç duyduğunu belirtmiştir. Bunun nedenlerinden bazılarını ise ulaşımın (1) ekonomi için kritik element olmasına ve (2) insan gruplarının toplanma mekanı olmasına bağlamıştır.

Güvenlik, ulaşım sisteminin performansını (1) kullanıcıya maliyetiyle, (2) güvenli/güvenilir olmasıyla, (3) hızıyla, (4) elverişliliğiyle, (5) bağlanabilirliğiyle, (6) emniyetiyle ve (7) erişilebilirliğiyle etkilemektedir (Polzin, b.t.).

Literatür kapsamında karşılaşılan çalışma gruplarından bir tanesi; trafik kazalarının belirli zaman dilimlerinde pik yapıp yapmadığını araştıran çalışma grubudur. Bu araştırmacılardan bir tanesi de Folkard (1997) olup; trafik kaza risklerinin belirli bir zamanda pik yapıp yapmadığını ölçmüştür (bkz. Grafik 1.). Bu çalışma zaman içinde ulaşım işletmelerindeki kaza riskinin nasıl değiştiğini incelemiş olup; bununla birlikte bu farklılaşmanın nedenlerinin altını çizmiştir (Folkard, 1997, s.417). 
Grafik 1. Günün Saatleri İtibariyle Trafik Güvenliğinin Durumu

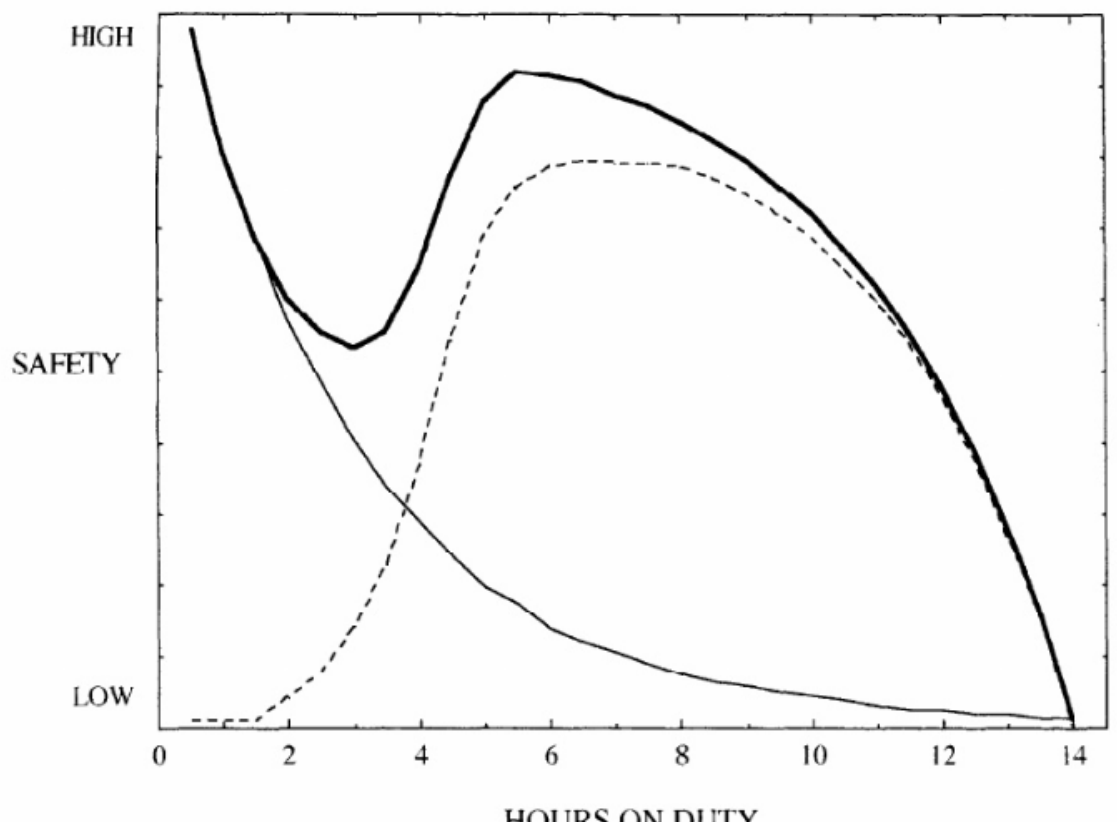

HOURS ON DUTY

Fig. 10. Schematic figure illustrating how the complex trend in safety (inverted risk, bold line) may reflect the additive influence of two

Kaynak: Folkard (1997, s. 428).

Folkard (1997), sürücülerin ne kadar süredir direksiyon başında olduğunun çok da araştırılmadığını belirttiği çalışmasında; trafik kazalarının günün belli saatlerinde ve belli görevlerde sabit olarak geçici pik yaptığ1 "kara saatlerin" ya da "kaza risklerinin" olduğu sonucuna ulaşmıştır (Folkard, 1997, s.429).

Ghosh, Parida ve Uraon (2004) kazaları gün içerisindeki zaman dilimlerine göre inceleyen araştırmacılardandır. Ghosh, Parida ve Uraon (2004) sabah 6-10.00 arasını okul ve işe gidenlerin pik saati, (2) 10-14.00 arasını ve (3) 14-18.00 arasını ev hanımlarının alışveriş saati trafiğii, (4) 18-22.00 arasını akşam trafiği, (5) 22.00-06.00 arasını gece olarak ayrıştırmıştır. Kazaların daha çok 18.00-22.00 saatleri arasında meydana geldiği tespit edilmiş olup; bunun nedeninin akşama bağlı aydınlatma yetersizliği olduğu düşünülmüştür. Ağır yaralanmaların sabah 10.00 ve 18.00 aralığında; ölümlü kazalarınsa sabah 18.00-22.00 arasında olduğu tespit edilmiş olup; dolayısıyla yetersiz trafik yönetiminden sözedilebilir (Ghosh, Parida ve Uraon, 2004, s.50-51). 
Diğer bir çalışma grubu ise ulaşım maliyetlerinin içerisinde güvenlik amaçlı maliyetleri araştıran gruptur. Bu araştırmacılardan biri olan Savage (2013) güvenliğin ulaşım maliyetlerinin büyük bir bölümünü kapladığını belirttiği çalışmasında otomobillerin maliyetlerinin pek çok güvenlikle alakalı tasarım nedeniyle arttığını ifade etmiştir. Ticari ulaşım sağlayıcıları aksilikleri azaltacak personel eğitimine ve yüksek kalitede malzemeye yatırım yapmaktadır (Savage, 2013, s.3). Shafabakhsh vd. (2017) de taşıt hızı ve sayısı artmasına rağmen, yol kalitesinin yeterince geliştirilmediğini ve taşıtların güvenlik standartlarının istenilen seviyeye gelmediğini ifade etmiştir (Shafabakhsh vd., 2017, s.297).

Trafik polis noktalarını ele alan araştırmacılar, trafik kaza riskine yönelik çalışma yapan araştırma grubunun diğer bir bölümünü oluşturmaktadır. Autubi (2012) bunlardan biri olup; Nijerya'nın Lagos bölgesinde; trafik kazalarının nasıl azaltılabileceğini araştırmıştır. Araştırmacı (1) yol uzunluğu $(\mathrm{km})$, (2) güvenlik algısı ve (3) nüfus değişkenlerinin trafik kazalarını \%97 oranında açıkladığını tespit etmiştir. Çoklu regresyon analizi kullanılan çalışmada; 1970-2001 yılları arasındaki yol uzunlukları $(\mathrm{km})$ kullanılmıştır. Yol güvenlik algısı dummy değişkendir. Üç değişkenin seçilme nedeni, verinin uygunluğu nedeniyledir. Alkollü araç kullanımı, hız aşımı ve dikkatsiz sürücü değişkenleri veri eksikliği nedeniyle kullanılamamıştır (Autubi, 2012, s.252).

Çalışma sonucunda yeni yol inşa etmenin trafik kazalarını arttırdığı tespit edilmiştir. Bununla birlikte; Nijerya'nın trafik polis departmanının, Nijerya sürücü nüfusuna ve yol ağına göre çok küçük olduğu tespit edilmiştir. Yoğun nüfusun olduğu ve motorize alandansa; ana yollarda polis gücü daha fazladır. Çalışma sonucunda trafik polis noktalarının rasyonalize edilmesi, trafiği azaltacak prosedürlerden biri olarak tespit edilmiştir (Autubi, 2012, s. 255-256).

Fenta ve Workie (2014) Etiyopya Bahir Dar' daki çalışmalarında; kazaların \%62.2'sinin polislerin işini zayıf yapmasından kaynaklandığını tespit etmiştir. Çalışma sonucunda sürücünün yaşı arttıkça kaza riskinin minimize olduğu tespit edilmiştir (Fenta ve Workie, 2014, s.93-94). Sürücünün eğitim düzeyi arttıkça, kaza riski azalmaktadır. Emniyet kemeri kullanımı arttıkça, kaza riski azalmaktadır. Sorumluluk sahibi insanların (yayaların) kaza riskini azalttığ1 tespit edilmiştir (Fenta ve Workie, 2014, s.95-96).

Mulkat Ajibola (2015) ise Nijerya' daki trafik kaza riskini anlamak için (1) nüfus, (2) trafiğe kayıtlı araç sayısı, (3) yol altyapısı ve (4) yoldaki kaza sayısının incelenmesi gerektiğini ifade etmiştir (Mulkat Ajibola, 2015, s.9). 
Bir diğer araştırma grubu ise kazaları yaya ve taşıt kazaları olarak ele alan gruptur. Bu araştırmalardan bir tanesinde Yalçın (2015); yaya kazalarının yoğunlaştığı noktaların kent planlaması çalışmalarında ve kent içi ulaşım projelerinde yol güvenliği konusunda vazgeçilmez bir bilgi kaynağı olduğunu ifade etmiştir (Yalçın, 2015, s.13).

Ulaşım ve trafik güvenliğinde kullanılan yöntem ve programlara ilişkin yapılan çalışmalar da başka bir çalışma grubudur. Kundakçı (2014), trafik kazaları konusundaki literatürü 3 ayrı başlık altında incelemiş olup; trafik güvenliği analiz metodları, yaya güvenliği analizleri ve trafik kazalarının en çok yaşandığı noktaları bulmaya yönelik analizler olarak incelemiştir. Erdoğan vd. (2008) kazalar için uygulanabilecek kaza analizlerini kesişim analizi, segment analizi, kümelenme analizi, yoğunluk analizi, doku analizi, yaklaşık analiz, mekânsal sorgulama ve mekânsal kaza analizi modelleme teknikleri şeklinde özetlemiştir (Erdoğan vd., 2008, s.175).

Yalçın (2015) ise mekânsal analiz setleri ve tehlikeli bölgeleri tespit eden araçların; coğrafi bilgi sistemleri (CBS) yazılımının içinde yer aldığın ifade etmiştir (Yalçın, 2015, s.6). Fenta ve Workie (2014) Etiyopya Bahir Dar'daki çalışmalarında; ki-kare testi, binary logistic regresyon modeli ve descriptive istatistikleri kullanmıştır (Fenta ve Workie, 2014, s.93). Selvasofia ve Arulraj (2016) çalışmalarında Coimbatore bölgesindeki en savunmasız kaza noktalarını tespit etmeye çalıştıkları çalışmalarında; kaza noktalarının yelpazesini çizmek için weighted overlay analizini kullanmışlardır.

Songpatanasilp vd. (2015) çalışma kapsamında dört çeşit model kullanmışlardır. Bunlar poisson regresyon modeli, negatif binomial regresyon modelleri, zero-inflated poisson regresyon modelleri ve zero-inflated negatif binomial regresyon modelleridir (Songpatanasilp vd., 2015, s.11).

Shafabakhsh vd. (2017) çalışmasında, mekânsal ve zamansal analizlerin trafik kazalarının en çok olduğu noktaların tespitinde ve bu noktaların güvenlik amacıyla geliştirilmesinde çok kullanışlı olduğunu ifade etmişlerdir (Shafabakhsh vd., 2017, s.291).

Shafabakhsh vd.'nin (2017) çalışması nearest neighbourhood analizi ve K-functionın birleşimi olup; kent kazalarının dağılımına ve kümelenmenin varlığına yatırım yapmaktadır. Buna ek olarak Kernel Density kestirimi ile kent ağı üzerindeki tehlikeli bölümler tanımlanmaya çalışılmıştır (Shafabakhsh vd., 2017, s.297). 
Bir grup çalışmada taşıt türünü dikkate alan çalışmalardır. Ghosh, Parida ve Uraon (2004) çalışmalarında; trafik kazalarını incelerken, taşıt türünü de dikkate almışlardır. Taşıtları üç kategoride inceleyen araştırmacllar; (1) kamyon, otobüs ve traktörleri ağır taşıtlar; (2) otomobil, jeep, kamyonet, oto-çekçek ve taksiyi orta taşıtlar, (3) motor, bisiklet ve scooterı hafif taşıtlar olarak gruplandırmışlardır. Çalışma sonucunda orta taşıtlardan kaynaklı kazaların daha fazla olduğu tespit edilmiştir (Ghosh, Parida ve Uraon, 2004, s.48-49).

Yol geometrik dizaynı da literatür kapsamında incelenen faktörlerden bir diğeridir. Çepni ve Arslan (2017, s.23) yol geometrik dizaynındaki gelişmelerin ölümcül kazaları azaltacağını ifade etmişlerdir. Kocaeli'deki çalışmada bölgedeki en kritik yol bölümü \%18'lik hafif yüksek eğime sahip Gazanfer Bilge Bulvarı olarak tespit edilmiştir (Çepni ve Arslan, 2017, s.21).

Trafik kazalarını azaltmak için yapılabilecekleri tespit eden çalışmalar da mevcuttur. Bunlardan bir tanesi de Selvasofia ve Arulraj'ın (2016) çalışmalarıdır. Bu çalışmada trafik kazalarını azaltmak için öneriler (1) şerit sayısını 2'den 4'e çıkarmak, (2) yayaların güvenliği için yolun iki tarafında yaya izi oluşturmak, (3) yeterli drenaj sağlamak, (4) diğer taşıtların durak noktalarında bekleme ve gecikme yapmasını önlemek için, ayrı otobüs kolları sağlamak, (5) taşıt hızını azaltmak için uygun zorlukta ölçütler almak, (6) yol kullanıcılarının güvenliği için yoldaki yamaları kaldırmak ya da onarmak, (7) U dönüşlerini azaltmak ve uygun uzunluk ve genişlikte orta açıklıklar oluşturmak ve (8) T kavşaklarda gerekli işaret panoları oluşturmak şeklindedir (Selvasofia ve Arulraj, 2016).

Çalışmada otobüs durakları odağa alınarak $500 \mathrm{~m}$. yarıçaplı daireler oluşturulmuştur. Bu daire içinde kalan alanda trafik kaza noktaları tespit edilmesi durumunda; kaza kaynaklı trafik sıkışıklığını minimize etmek için otobüs durağı kaldırılmıştır (Selvasofia ve Arulraj, 2016).

Kavşaklar ve ortalama trafik hızının da trafik kazalarını düşürücü etkisi olduğu bulunmuştur. Trafik hızı azaldıkça kazaların azalması normal bir sonuçtur (Songpatanasilp vd., 2015, s.18).

Kundakçı (2014) kaza noktalarıyla, kavşak noktalarının tasarımları arasındaki ilişkiyi anlayabilmek için kavşak türlerinin döner kavşak, dörtlü kavşak, üçlü kavşak vb. ayrıştırılması gerektiğini ifade etmiştir. Eğer mümkünse kavşak noktalarındaki sinyalizasyonun da trafik ışıklarının etkisini anlamak için dikkate alınması gerektiğinden bahsetmiştir. Yol bölümünün hız statüsü, yol 
türü ve şerit sayısı da dikkate alınabilecek diğer değişkenlerdir. Kaza noktalarındaki kaza sayısındansa kazadaki yaralı ve ölümlü sayısı da dikkate alınabilecek diğer değişkenlerdir (Kundakçı, 2014, s.128-129).

Hashimoto, (2005) yol geometrisi ve çevresel faktörlerin de önemli olduğunu ifade etmiş olup; ortalama yol genişliği, şerit sayısı, kaldırımlar ve yolun parlaklığı (aydınlığı) yaya kazalarında önemli etkiye sahiptir (Hashimoto, 2005, s.59). Bununla birlikte bu çalışma trafik hacmi ve yaya kazaları arasındaki ilişkiyi açıklayamamıştır (Hashimoto, 2005, s.62).

Literatür kapsamında şehir planlamayla en çok ilişkisi olan tespitlerden biri de arazi kullanım durumuyla trafik kazaları arasında kurulan ilişkidir. Songpatanasilp vd. (2015) trafik kazalarının nedenlerinden yol boyunca bulunan arazi kullanım durumlarına odaklanmıştır. Çalışma kapsamında ilkokul, banka, tiyatro, eğlence alanları, alışveriş merkezleri, hastaneler, okullar ve üniversiteler, istasyonlar, cazibe merkezleri, mağazalar vb. arazi kullanım verisi toplanmıştır. Yolla ilişkili değişkenler; yolların türüne göre uzunlukları, yol genişlikleri, günlük trafik hacmi ve trafik hızı ayrıştırılmıştır. Tatil ve haftasonu kazaları ayrılmıştır (Songpatanasilp vd., 2015, 11).

Çalışma sonucunda trafik kazalarının ticaret alanlarında daha sık yaşandığı tespit edilmiştir. Trafik hacminin daha düşük olduğu ve arazi kullanımın sadece konut alanıyla sinırlı olduğu az katlı konut alanlarında ise trafik kazalarının daha az yaşandığı tespit edilmiştir (Songpatanasilp vd., 2015, s.20).

Dükkan, hastane, spor faaliyetleri ve cazibe merkezlerinde insan ve taşıt sayısı arttığından, trafik kazaları da artmaktadır. İlkokul, banka ve eğlence merkezlerinde ise trafik kazalarının daha az olduğu tespit edilmiştir. İlkokul bölgelerinde öğrenci olmasına rağmen sonuçların negatif çıkması şaşırtıcıdır. Ancak okulların çevresinde çeşitli güvenlik önlemlerinin zaten alındığı düşünüldüğünde; bu durum normal görülebilir (Songpatanasilp vd., 2015, s.18).

Banka çevrelerindeki trafik kazaları ise tatil günleri ve hafta sonlarında negatif çıkmış olup; bunun nedeni bankaların o günlerde kapalı olması olarak açıklanabilir. Ek olarak Tokyo'daki bankalar daha çok merkezi iş alanında olup; bankalar, merkezi iş alanı bölgelerine vekil düşünülebilir (Songpatanasilp vd., 2015, s.18).

Kavşakların negatif çıkmasının nedeni; kavşak sayılarının konut alanlarında, diğer arazi kullanım durumlarına göre daha büyük olmasıdır. Bu durum konut alanlarında trafik kazalarının daha az olmasını açıklar. Trafik hacmi arttıkça trafik kazaları da artmaktadır. Bu da beklenen bir sonuçtur (Songpatanasilp vd., 2015, s.18-19). 
Kundakçı (2014) da yapılı çevre ve trafik kazaları arasında önemli bir ilişki olduğunu belirttikleri çalışmasında; kentsel arazi kullanım durumunun trafik kazaları üzerindeki etkisini ifade etmiştir. İş alanları, ticari alanlar, kültürel aktivite alanları gibi trafik üreten belli alanlar olduğunu belirten Kundakçı (2014) bu nedenle yapılı çevrenin trafik güvenliği analizlerindeki öneminden bahsetmiştir (Kundakçı, 2014, s.10).

Hashimoto (2005) çalışmasında konut alanlarında yaya kazalarında artış olduğunu tespit etmiştir. Çalışma sonucunda düşük yoğunluklu konut alanları sabitken, orta yoğunluklu alanlarda 2 kat, yüksek yoğunluklu alanlarda 3 kat daha fazla yaya kazası olduğu tespit edilmiştir. Çalışma sonucunda nüfus yoğunluğu da yaya kazalarıyla pozitif ilişkili bulunmuş olup; arazi kullanım durumuyla yer değiştirebileceği (yerine kullanılabileceği) ifade edilmiştir (Hashimoto, 2005, s.54).

Kent makroformuyla ve şehir planlamayla doğrudan ilişkilendirilebilecek değişkenlerden birisi de yol ağıdır. Shafabakhsh vd. (2017) çalışmalarında karayollarının kent merkezinden dışarı doğru uzamasının; kaza riskini azalttığını ifade etmiştir (Shafabakhsh vd., 2017, s.295).

Gelişmekte olan ülkelerde; kaza nedeni olarak sadece kaza sayısı ve kaza türü kayıt altına alınmakta olup; gerçek nedenler gözardı edilmektedir. Yol geometrisi ya da çevresel faktörler, kaza nedeni olarak kayıt altına alınmamaktadır. Çünkü idareler arasında kaza nedenleriyle ilgili belirsizlikler bulunmaktadır (Çepni ve Arslan, 2017, s.18). Shafabakhsh vd. (2017) trafik güvenliği konusundaki anlamlı mekânsal analizler için çalışmaların 3 ya da 5 yıllık dönemleri kapsaması gerektiğini belirtmiştir (Shafabakhsh vd., 2017, s.298).

Dolayısıyla ulaşım güvenliğini sağlamak için kullanılabilecek güvenilir bir mekânsal veri tabanı; trafik kazalarının önlenmesinde alınacak önlemleri doğru bir şekilde belirlemek açısından büyük önem taşımaktadır.

\section{Tartışma}

Ulaşım güvenliği konusunda yapılacakların başarıya ulaşması; öncelikle merkezi ve yerel yönetimlerin tam desteğinin alınmasına ve hedeflenen çalışmaların ülke ulaşım politikalarına dahil edilmesine bağlıdır. Bu hedefler; yasa ve yönetmeliklerle tanımlanmalı; planlama araçlarının da yardımıyla çözüme kavuşturulmalıdır. 
Genel olarak bakıldığında literatür taramalarının ortaya koyduğu verilerden bazıları planlama disiplininin araçlarıyla çözülebilecek özellikler taşımaktadır. Bazıları ise planlama disiplininin çalışma alanı dışında, farklı uzmanlık alanlarını ilgilendiren konulardır.

Çalışmanın bu bölümünde kentte ulaşım güvenliği açısından tehlike oluşturabilecek faktörler aktarılmaya çalışılacak (Tablo 1.); güvenlik sorunlarının çözümüne yönelik yapılabilecekler planlamayı bir "araç" olarak odağa koyarak tartışılacaktır.

Bir şehir plancısının planlama çalışmalarında en çok kullandığı araçlardan birisi; kentin projeksiyon yılında sahip olacağı nüfusunu; planladığı konut bölgelerine dengeli bir şekilde dağıtmak için kullandığı net ve brüt yoğunluk kararlarıdır.

Söz konusu net ve brüt yoğunluk kararlarl; belirli bir alanda yaşayacak insan sayısını belirlediği için; bu alanda oluşacak ulaşım arz ve talebi ile trafik yoğunluğunu da belirler niteliktedir. Oluşacak trafik yükü nedeniyle kaza riskinin artması, parklanma problemleri ya da sağlık açısından ortaya çıkabilecek hava, gürültü ve titreşim kirlilikleri; nüfus nedeniyle ortaya ç1kabilecek diğer yan etkilerdir.

Dolayısıyla şehir plancıları; nüfus yoğunluğuna ilişkin kararları verirken; oluşturdukları yapı adalarının çevresindeki trafik yükünü de dikkate alarak, toplu taşıma araçlarına hizmet edecek güzergahı, alana ulaşacak toplu taşıma türlerini (raylı sistemler, brt, otobüs, dolmuş, minibüs vs.), otopark ihtiyacını ve yol genişliklerini de öngören bir planlama çalışması gerçekleştirerek; uygun araçları da ortaya koymalıdır. Bununla birlikte trafiği toplayacak ve dış arterlere aktaracak ulaşım sistemini de ulaşım hiyerarşisi içerisinde kurgulamalıdır.

Kentte ulaşım güvenliğini etkileyebilecek planlama araçlarının en önemlilerinden bir diğeri ise arazi kullanım türüne yönelik yapılan atamalardır. Arazi kullanım kararının konut ya da çalışma alanı olması, sanayi ya da ağaçlandırılacak alan olması; o alanın oluşturacağı ulaşım arz ve talebi ile buna bağlı olarak ortaya çıkacak trafik yükünü etkiler. Nüfus yoğunluğu atamalarına benzer şekilde trafik yüküne bağlı olarak otopark/yol üstü vb. parklanma sorunları, hava, gürültü ve titreşim kirlilikleri, trafik kaza riskleri; arazi kullanım türü nedeniyle oluşabilecek diğer dışsallıklardır.

Özellikle yeni planlanan alanlarda ortaya çıkabilecek sorunlardan bir tanesi de yapı adası uzunluğuna bağlı olarak sokakların çok sık kesişmesi problemidir. Kesişim noktası ya da kavşak noktalarındaki artış; trafik kaza riski oluşturması nedeniyle önemlidir. Mevcut ya da öneri fark etmez, bazı 
sokakların yayalaştırılması sonucu motorlu taşıt trafiğinin kavşak noktaları nedeniyle biraraya gelme sıklığı azaltılabilir. Yapı adası uzunlukları da bu amaçla kullanılabilecek planlama araçlarından bir tanesidir. Ancak çok uzun yapı adaları oluşturulmamasına da dikkat edilmelidir.

Trafik hızını azaltmak için kullanılan yöntemlerden bazıları hız tümsekleri oluşturmak, yol hattının açısıyla oynamak ve yol malzemesini trafik hizını düşürecek şekilde değiştirmektir. Buradaki amaç daha çok meskûn mahallerde olası trafik kaza riskini azaltmaktır. Yolun derecesine ve kullanıc1sına bağlı olarak trafik hızı değişebilir. Yaya yollarında, motorlu taşıttan arındırılmış alanlardaki trafik hızı ile, mahalle aralarında sokaklardaki trafik hızı ve transit trafiği taşıyan otoyol ya da çevre yolu gibi daha üst kademe yollardaki trafik hızı birbirinden farklıdır. Yol malzemesi ve hız tümsekleri daha çok alt kademe yollarda trafik hızını düşürmek için kullanılabilecek yöntemlerken; yol hattının açısıyla oynamak otoyol ya da çevre yolu gibi sürat yollarında dikkate alınabilecek yöntemlerdir. Bu yöntemleri planlama araçları haline getirerek planlama çalışmalarında kullanabilmek trafik güvenliği açısından büyük öneme sahiptir.

Ulaşım yapılarının çok büyük alanlar kaplaması; bazı durumlarda ıssız alanların ortaya çıkmasına neden olabilir. Bu durumda kent güvenliği açısından sorun oluşturabilecektir. Aktarma istasyonları, tır parkları vb. alanlar günün belli saatlerinde ve haftanın belli günlerinde güvensiz alanlar haline gelebilir. Dolayısıyla ıssız olması nedeniyle sorun oluşturabilecek alanlarda, bu alanları canlı tutacak başka arazi kullanım türlerinin önerilmesi; ya da nüfus yoğunluk kararlarının değerlendirilmesi; ulaşım yapılarının özellikleri nedeniyle kent güvenliği açısından ortaya çıkabilecek sorunların aşılmasında yardımcı olacaktır. Bir diğer yöntem de toplu taşıma duraklarının organizasyonuyla ilgilidir. Toplu taşıma durakları doğal gözetim hissi uyandırarak, suçu/suçluyu caydırıcı etki uyandırabilir.

Joewono, T. B. ve Kubota, H. (2006) çalışmalarında toplu taşımanın bir araçta çok sayıda yolcu taşıması nedeniyle yüksek güvenlik riski oluşturduğunu ifade etmişlerdir. Çalışma Endonezya'nın Bandung kentinde paratransit yolcuları ve sürücüleriyle, paratransit kullanıcısı olmayan ve sivil hizmetlilerin güvenlik algısını ölçmeye yöneliktir. Çalışmada faktör analizi yöntemi kullanılmıştır. Çalışma sonucunda kullanıcıların dikkati ve anlayışının, koşulları iyileştirmede en önemli faktör olduğu tespit edilmiştir (Joewono, T. B. ve Kubota, H., 2006, s.86).

Trafik hızı; ulaşım güvenliğini tehdit eden en önemli faktörlerden birisidir. Dolayısıyla yol hiyerarşisi içerisinde daha alt kademe yollar arasındaki 
yaya ve taşıt geçişleri ne kadar sıksa; trafik hızı arttıkça özellikle üst kademe otoyol, çevre yolu gibi sürat yollarında; yaya ve taşıt geçişleri minimize edilmelidir. Yaya ve taşıt geçişleri ve karşılaşmalarının minimize edilmesinde kullanılabilecek yöntemler alt ve üst geçitler ve kavşak noktaları arasındaki mesafeler olup; planlama çalı̧̧malarında dikkate alınması gereken önemli araçlardan bir tanesidir.

Özellikle taşıt yollarındaki bitkilendirme; taşıtın dönüş yapacağı kavşak noktalarına yaklaştıkça büyük önem taşımaktadır. Bu alanlarda kullanılan bitkilerin görüşü engelleyecek türde olması; araçların geçişi sırasındaki kaza riskini arttırmaktadır. Dolayısıyla kullanılacak bitkinin türü ve görüş açısını engellemeyecek açıklığın sağlanması ulaşım güvenliği açısından büyük önem taşımaktadır. Bazı durumlarda plancı, bitkilendirmeyi riskli bulduğu noktaları tasarım araçlarını kullanarak engellemelidir.

Benzer bir sorun çekme mesafelerinin yeterli uzaklıkta ve kaldırım genişliklerinin ise yeterli uzunlukta bırakılmaması ya da dönüş noktalarına bir aracın park etmiş olması nedeniyle görüşü engellemesi sonucu da ortaya çıkabilmektedir. Bu gibi durumlarda da plancılar farklı araçlar geliştirmeli, araç parklanmasına engel olacak tasarım ögelerini planlama çalışmalarına eklemelidir. Örneğin kavşak noktalarına araç parklarını önlemek amacıyla, uygulama imar planı ya da daha detay çalışmalarda kaldırım genişlikleri düzenlenebilir ya da çekme mesafeleri düzenlenirken köşe yapılar daha geriden başlatılarak; kaybettikleri emsal değerleri kat yoğunluklarından karşılanabilir.

Sokak aydınlatması kent güvenliği açısından önemli başka bir değişkendir. Karanlık alanlar saklanma mekanları oluşturması nedeniyle olası suç mahalleri olarak düşünülebilir. Aydınlatma sokak lambalarıyla çözülebileceği gibi; yapıların yola bakan cephelerinin sağır cephe olarak düzenlenmemesi de kullanılabilecek yöntemlerden bir diğeridir. Sokakların aydınlatma elemanları ile aydınlatılması ya da yola bakan cephelerin sağır cephe olmaması; doğal gözetime imkan tanıması suçu engelleyici etkisi olan faktörlerdendir. Dolayısıyla planlama aracı olarak kent güvenliğini sağlaması açısindan önemlidir.

Çıkmaz sokaklar da kent güvenliği açısından olumsuz tanımlanabilecek alanlar olup; imar planlarıyla çımaz sokaklar oluşturulamaması; bu anlamda önemli bir araçtır. Sadece tarihi özelliği nedeniyle korunması gerekli alanlarda, dokuyu bozmamak için çıkmaz sokaklara müdahale edilmesi uygun görülmez. 
Eğim analizleri bize drenajın iyi çalışmayacağı yerleri gösterirken; taşıtların en iyi şekilde seyahat edebileceği, taşıtların ya da insanların tırmanmakta zorlanacağı ve teras yapıların inşaatına uygun olan alanları gösterir. Dolayısıyla ulaşım güzergahları önerilirken; yol eğimi, taşıtların hareketlerine uygun bir şekilde önerilmelidir. Bununla birlikte; taşıtlar eğimli bir yolda seyahat ederken; virajlı kesimlere yapılan yol bağlantıları ya da site giriş-çıkışları; trafik güvenliği açısından sorun oluşturmaktadır. Bu nedenle planlama çalışmalarında yol eğimine ve virajın açısına bağlı olarak kullanılabilecek yöntemler de geliştirilmelidir.

Taşıtların parklanma sorunları da trafik güvenliği açısından dikkate alınması gereken durumlardan biridir. Planlama çalışmalarında gerekli otopark alanlarının doğru saptanmamış olması ya da arazi kullanım türünün üreteceği park alanı talebinin doğru kestirilememiş olması, ya da önerilen otopark alanlarının yer seçimindeki hatalar; taşıtların şerit ihlali yapacak şekilde yol üstüne park etmelerine neden olmaktadır. Özellikle kullanım yoğunluğu yüksek olan ticaret alanlarında, hastane, okul vb. arazi kullanım türlerinin biraraya geldiği noktalarda çift sıra parklanmayla bile karşlaşılabilmektedir.

Bazı durumlarda kavşak noktalarına yakın park eden araçlar görüşü engellemekte ve trafik kazalarına neden olabilmektedir. Dolayısıyla otopark arzı ve yer seçimine yönelik çalışmalar şehir plancıların kentteki ulaşım güvenliğinin sağlanması açısından üzerinde durmaları gereken en önemli konulardan bir diğeridir.

Tablo 1. Ulaşım Güvenliği Kapsamında Mevcut Verilere İlaveten Önerilebilecek Planlama Araçları

\begin{tabular}{l}
\hline Ulaşım Güvenliği Açısından Geliştirilebilecek Araçlar \\
\hline 1.Net ve brüt nüfus yoğunluk kararları \\
\hline 2.Planla öngörülen arazi kullanım türleri \\
\hline 3. Yapı adası uzunluğuna bağlı sık kesişim/kavşak noktaları \\
\hline $\begin{array}{l}\text { 4. Yol malzemesi, hız tümseği, yol hattının açısı (kilit parke vb. trafik hızını düşürücü öne- } \\
\text { riler) }\end{array}$ \\
\hline $\begin{array}{l}\text { 5. Ulaşım yapılarının ıssız mekanlar oluşturması bakımından (arazi kullanım türü/toplu } \\
\text { taşıma durağı/nüfus yoğunluğu çaprazlanması) }\end{array}$ \\
\hline 6. Trafik hızı \\
\hline 7.Refüj bitkilendirmesi \\
\hline 8.Karanlık alanlar \\
\hline 9.Çıkmaz sokaklar \\
\hline 10. Eğimli yollar \\
\hline 11. Parklanma sorunları
\end{tabular}


12. Yaşlı, hamile, çocuk, engelli vb. diğer grupların ulaşım güvenliği

13. Ulaşım türleri ve aralarındaki ilişkilerin kurgulanması açısından

14. Acil durum araçları ve yol özellikleri itibariyle

15. Oluşturduğu sağlık sorunları açısından (yakıt türü nedeniyle hava kirliliği, gürültü kirliliği, titreşim)

16. Yol genişlikleri

17. Yol malzemesinin bakımsızlı̆̆

18. Tek yön uygulamaları

19. Toplu taşıma ve durak noktaları itibariyle

20. Yaya ve taşıt alt ve üst geçitleri

21. Büyük araçların parklanma sorunu

22. Trafik polis noktaları ve caydırıcı faktörler

Özellikle yaşlı ve engelli gibi fiziksel şartları olumsuz olanlar için bazı yol düzenleme standartları bulunmakta olup; kaldırım yükseklikleri ve rampalara ait düzenlemeler bunlardan bazılarıdır. Rampaların sonuna park etmiş araçlar da engellilerin erişimini kısıtlayan faktörlerden birisidir. Engelli, yaşlı, hamile, çocuklu vb. erişim için diğer insanlara göre daha fazla çaba sarfetmesi gereken insanların güvenli bir şekilde ulaşımlarını sağlayabilecekleri ortamları tasarlamak da yine şehir planlama ve kentsel tasarım uzmanlarının görevidir. Bununla birlikte küçük çocukların motorlu taşıt trafiğine açık yollara kolay erişimini engelleyecek bariyerlerin oluşturulması da yine planlama çalışmalarında değerlendirilebilecek yöntemlerdir.

Ayhan ve Çubukçu (2007) çalışmasında toplu taşıma durağı varlığının doğal gözetim alanları oluşturması nedeniyle hırsızlık suçunu azalttığı sonucuna ulaşmışlardır. Dolayısıyla bazı ulaşım ögeleri, farklı suç kategorileri üzerinde de etkili olmaları nedeniyle, kent güvenliğine olumlu katkı sağlayan elemanlardır (Ayhan ve Çubukçu, 2007, s.74-75).

Ulaşım tür seçimi trafik kazalarında etkisi olan değişkenlerden bir diğeridir. Ulaşım sisteminin kullanıcılarını yaya, bisikletli, otomobil, otobüs, metro, metrobüs, tren, vapur, uçak vb. açıklayabiliriz. Ulaşım türleri arasındaki geçişleri sağlayan yaya geçitleri, alt ve üst geçitler, tüneller, köprüler, aktarma istasyonları, katlı kavşaklar vb. detaylandırabiliriz. Ulaşım güvenliği açısından, ulaşım türleri arasındaki geçişlerin planlanması ve aktarma istasyonlarının, alt ve üst geçitlerin planlanması büyük önem taşımaktadır. Örneğin raylı sistemlerle, karayolu bağlantılarının hemzemin olmaması; yani geçişlerin alt ya da üst geçitlerle sağlanması; trafik kaza riskini azaltması bakımından önemlidir. Ya da raylı sistemlerin hemzemin olduğu noktalarda, yaya girişlerini engelleyecek şekilde güvenlik tedbirleri alınması da 
trafik kazalarını azaltacak diğer etkili yöntemlerdendir. Bununla birlikte bisikletlilerin yayalarla ve taşıtlarla olan geçitleri planlanırken; kavşak çözümleri trafiği en az etkileyecek şekilde gerçekleştirilmelidir. Park et devam et sistemine uygun her ulaşım türü için gerekli park alanlarının yer seçimi de ulaşım güvenliği açısından önemli olan faktörlerden bir diğeridir. Yer seçimin yürünebilir olması gerekmektedir.

Çöplerin toplanması, hasta ya da yaralı nakillerinin gerçekleştirilmesi, yangin söndürme faaliyetlerinin gerçekleştirilebilmesi gibi kamu hizmetlerinin güvenli bir şekilde sürdürülebilmesi için; ulaşım altyapısının bazı özel şartları taşıyor olması gerekmektedir. Yol genişliklerinin acil kurtarma araçlarının ya da diğer araçların dönüşüne izin verecek genişlikte olması; yapıların çıkmalarının kamu hizmetlerinin gerçekleşmesine engel olmayacak yükseklikte olması, yol eğiminin bu tip ağır araçların çıkmasına engel olmayacak şekilde düzenlenmesi, acil durumlarda her yapıya ulaşımı mümkün kılacak bir parselasyonun yapılmış olması gerekmektedir.

Planlama meslek alanının sorumluluk alanını aşıyor gibi görünse de; taşıtların kullandıkları yakıt türleri de kent sağlığının güvende olması açısından büyük önem taşımaktadır. Son dönemde bu nedenle dizel araç girişini yasaklayan ülkeler, ya da motorlu taşıt trafiğine izin vermeyen kentler bu duruma örnek olarak gösterilebilir. Gürültü kirliliği de kent sağlı̆̆ın etkileyen başka bir faktör olup; bu konuda kabul edilebilir gürültü seviyeleri bulunmaktadır. Gürültü kirliliğini azaltabilmek amacıyla ağaçlandırma çalışmalarının yanısıra, kaldırım genişlikleri ve yapının yoldan çekme mesafesi bir planlama aracı olarak kullanılabilir. Bir diğer konu ise trafik kaynaklı titreşimler olup; özellikle yüksek titreşim düzeylerine neden olarak yapılarda hasar oluşturmasa dahi, insanları psikolojik olarak rahatsız edebilecek ağır taşıtlar için güzergah önerilerinde bulunulabilir. Bununla birlikte Ayhan ve Çubukçu'nun (2013) çalışmasında trafik kaynaklı titreşimleri azaltabilecek planlama araçları önerilmiştir. Çalışma kapsamında yapıya bitişik bir bahçe duvarı olması, yapının önünde açık alan olması, yapıya her iki tarafından bitişik daha az yükseklikte yapı olması, taşıt tekerleklerinin çaplarının aynı olması ve yapının önünde su kanalı olması titreşimi azaltıcı etkiye sahipken; yol kesişim noktasının artması, yapı büyüklüğünün artması, taşıt ağırlığının artması, eğim durumunun artmasının titreşimi arttırıc etkiye sahip olduğu tespit edilmiştir. Yapı avlusunun zemininin mozaik, toprak, taş, ahşap, beton ve kayrak taşından olması da sırasıyla titreşim düzeyini arttırıcı etkiye sahip bulunmuştur (Ayhan ve Çubukçu, 2013, s.113). 
Gelişme alanlarında yapının yoldan çekme mesafesi bir planlama aracı olarak kullanılabilecekken; özellikle tarihi özelliğe sahip alanlarda; trafik kaynaklı titreşime neden olabilecek faktörler daha detaylı çalışılmalı; yapıya yakın hendek, tümsek, ağaçlandırma vb. titreşim dalgasını kırarak azaltacak ve yapıya ulaşmasını engelleyecek önlemler alınabilir.

Yol genişlikleri; önemli bir planlama aracı olup; motorlu taşıtlar için olduğu kadar, yayalar ve bisikletliler için de yeterli genişliklerin planlanması gerekmektedir. Yolun niteliği de göz önünde bulundurularak, her ulaşım türüne özel standartların sağlanması, ulaşımın güvenli bir şekilde sağlanması açısından önemlidir. Mevcut ya da tarihi dokuda bu koşulları sağlamak yüksek kamulaştırma maliyetleri gerektirmesi nedeniyle imkansız gibi görünse de; özellikle yeni gelişme alanlarında ulaşım güvenliği açısından kullanılabilecek önemli bir planlama aracıdır.

Yol malzemesinin bakımsızlığ da ulaşım güvenliğini etkileyen önemli faktörlerden biri olup; trafik kaza oranlarının düşürülmesi açısından büyük önem taşımaktadır.

Sürücülerin yanlış noktalara park etmesi, yola çıkacak araçlar için kör noktalar oluşturması vb. nedenlerle trafik kazalarına neden olan faktörlerden birisidir. Planlı otoparkların giriş çıkış noktalarının kavşak noktalarına yakın olması ya da başka otopark girişleriyle çakışması vb. pek çok durum da trafik kazalarını arttıran faktörlerdendir. Planlı otoparkların iç düzenlemelerindeki hatalar da trafik kazalarına neden olabilmektedir. Trafik kazalarına neden olan faktörlerin başında hız gelmekte olup; plancı yol tasarımı yaparken; yol hattını belirli noktalarda hızı düşürecek şekilde şekillendirirse, yol kaplaması, tümsekler, yaya alt-üst geçitlerinin doğru planlanması, yol kavşak çözümleri, ticaret akslarındaki, hastane alanlarındaki parklanmalar vb. için trafik kazalarının azaltılmasında önemli çözümler olacaktır. Sürücünün dikkatini dağıtacak reklam panosu vb. için de belirli standartlara uyulması önem taşımaktadır.

Trafik kazalarına neden olan faktörlerden biri de servis araçları, dolmuş ve minibüs gibi belirli durak noktaları olmaksızın yolcu talebine göre hareket eden toplu taşıma araçları olup; bu taşıtların ulaşım sistemine ne şekilde adapte edilmesi gerektiği de tartışılması gereken bir konudur.

Ulaşım güvenliğini sağlamak için kullanılabilecek araçlardan biri de tek yön uygulamaları olup; özellikle yol genişliğinin yetersiz olduğu sıkışık alanlarda, trafiği rahatlatmak için kullanılan çözümlerden biridir. Bu uygulamalar daha çok tarihi dokuda kullanılırken; planlı gelişen yeni gelişme 
alanlarında talebe uygun yol genişliklerinin sağlanması durumunda, tek yön uygulamalarına gerek kalmayacaktır.

Günümüzde internetin yaygın kullanımıyla birlikte pek çok mal ve hizmetin satış noktalarına gitmeden alınması; alışveriş temelli yolculukların sayısını azaltırken; özellikle kargo firmalarına ait yolculukların ise artmasına neden olmuştur. Bununla birlikte de kargo firmalarının parklanma ihtiyacına yönelik sorunlar ortaya çıkmıştır. Planlama, günümüz koşullarına uygun hesaplamaları gözönünde bulundurarak çalışmalarını yapmalı; kargo firmalarının yer seçimine ya da parklanma problemlerine ilişkin de çözümler geliştirilmelidir.

Toplu taşıma araçları, genellikle özel araç yolculuklarına kıyasla daha güvenilir kabul edilir. Toplu taşıma araçlarının boyut ve ağırlıklarının da bunda etkisi bulunmaktadır. Toplu taşıma araçlarının kent içerisinde güvenli bir şekilde hareketi ise; güzergah planı yaparken; toplu taşıma araçlarına uygun yol genişliklerinin, yol eğiminin ve zemin malzemesinin olduğu yerleri tercih etmekle mümkün olur.

Toplu taşıma araçlarına ait durak noktalarının da yer seçimi ulaşım güvenliği açısından büyük önem taşımaktadır. Kavşak noktalarına yakın yerlerde bulunan durak noktaları trafik kazaları açısından risk oluştururken; farklı bir bakış açısıyla Ayhan ve Çubukçu'nun (2007) tespitini destekler şekilde; bir yerde toplu taşıma durağının olması doğal gözetimi arttırması nedeniyle suçu caydırıcı etki sağlayabilir.

Ulaşım güvenliği açısından incelenebilecek diğer bir ulaşım elemanı da; otoyollarda bulunan emniyet şeritleridir. Emniyet şeritlerinin sadece acil durumlarda kullanımına imkan tanıyan tasarım araçlarının kullanılması acil durum araçlarının ulaşımı açısından önemlidir. Bu konuda açılır-kapanır mantar sistemleri vb. araçlar incelenebilir.

Bununla birlikte yaya ve taşıtlara ait alt ve üst geçitlerin yer seçimlerindeki başarı; bu ulaşım elemanlarının kullanım oranını arttırarak; trafik kaza oranlarının düşmesinde etkili bir araç haline gelebilir.

Büyük araçların kent içerisinde, özellikle kavşak noktalarına park etmesi; kavşak noktalarını kullanan diğer sürücüler için kör noktalar oluşturmakta ve trafik kazalarına neden olabilmektedir. Dolayısıyla tur araçları, tırlar, kamyonlar, okul servisleri vb. araçların park problemlerinin çözülmesi, ulaşım güvenliği açısından büyük önem taşımaktadır.

Dolayısıyla ulaşım güvenliğini sağlamak için kullanılabilecek ancak araştırılması ve kullanım şekline karar verilmesi gereken çok sayıda plan- 
lama aracı bulunmaktadır. Bu planlama araçlarının araştırılarak uygun kullanım şekline karar verilmesi trafik kaza oranlarını azaltmada önemli katkı sağlayacaktır.

\section{Değerlendirme ve Sonuç}

Ulaşım güvenliğinin daha çok insan kaynaklı olduğu düşünülse de; mekanın doğru şekilde tasarımının pek çok güvenlik problemini minimize edeceği düşünülebilir. Dolayısıyla mekanın tasarımıyla ilgilenen uzmanlık alanlarına rehber niteliği taşıyacak bir kaynak oluşturulması, ulaşım güvenliğinin sağlanması açısından büyük önem taşımaktadır. Bu çalışma; literatüre ilaveten belirttiği değişkenleri tartışmaya açmak ve ulaşım güvenliğinin sağlanmasında kullanılabilecek değişkenlerin çerçevesini çizmek amacıyla gerçekleştirilmiştir. Genelleme yapmak gerekirse; literatürde bugüne kadar gerçekleştirilmiş çalışmalar belli başlıklar altında gruplandırılabilir. Bunlar;

(1) trafik kazaları ve arazi kullanım türü ilişkisini kuran çalışmalar (Songpatanasilp vd. (2015), Kundakçı (2014), Hashimoto (2005)),

(2) trafik kazaları ve nüfus yoğunluğu ilişkisini ortaya koyan çalışmalar (Hashimoto (2005), Autubi (2012)),

(3) trafik kazaları analiz yöntemlerine odaklanan çalışmalar (Kundakçı (2014), Erdoğan vd. (2008), Yalçın (2015), Fenta ve Workie (2014), Selvasofia ve Arulraj (2016), Songpatanasilp vd. (2015), Shafabakhsh vd. (2017)),

(4) trafik kazaları ve kent makroformu arasında ilişki kuran çalışmalar (Shafabakhsh vd. (2017)),

(5) trafik kazaları ve yol tasarımı arasındaki ilişkiye odaklanan çalışmalar (Çepni ve Arslan (2017), Selvasofia ve Arulraj'ın (2016), Songpatanasilp vd., (2015), Kundakçı (2014), Hashimoto, (2005)),

(6) trafik kazalarıyla trafik polis kontrol noktaları ve trafik polislerinin performansı arasında ilişki kuran çalışmalar (Autubi (2012), Fenta ve Workie (2014)),

(7) trafik kazalarıyla ulaşım güvenliği arasında ilişki kuran çalışmalar (Polzin (b.t.), Shafabakhsh vd. (2017)),

(8) trafik kazaları ve trafik kazalarının gerçekleşme saatlerini araştıran çalışmalar (Folkard (1997), Ghosh, Parida ve Uraon (2004)),

(9) güvenliğin ulaşım maliyetlerinin büyük bir bölümünü oluşturduğunu savunan çalışmalar (Savage (2013)), 
(10) trafik kazalarını yaya ve taşıt odaklı araştıran çalışmalar (Yalçın (2015)),

(11) trafik kazaları ve taşıt türü ilişkisini analiz eden çalışmalar (Ghosh, Parida ve Uraon (2004)).

Ancak bu çalışmalara ilaveten kullanılabilecek çok sayıda planlama aracı da üzerinde durulması gereken değişkenlerdir. Literatürde bahsedilen arazi kullanım türü ve nüfus yoğunlukları dışında planlama aracı olarak kullanılabilecek en önemli değişkenler çekme mesafeleri, kaldırım ve yol geniş̧likleridir.

Planlama ölçekleri bakımından bu konu daha çok 1/1000 uygulama imar planı ölçeği ve daha alt kademe detay ölçekler gibi görünse de; benimsenen ulaşım politikaları açısından düşünüldüğünde üst ölçeğin de konusu olduğu görülür.

Planlama mevzuatında ulaşım ve ulaşım güvenliğine ilişkin kullanılabilecek araçlar olsa da; ulaşım güvenliğini arttırmak amacıyla ne şekilde kullanılabileceği konusunda rehber niteliğinde bir çalışmaya henüz rastlanmamıştır. Trafik kazalarını azaltmaya yönelik rehber görevi görecek mekânsal değişkenlere atıfta bulunan çalışma sayısı da son derece azdır.

Daha önce de belirtildiği gibi; ulaşım güvenliği konusunda yapılacakların başarıya ulaşması; öncelikle merkezi ve yerel yönetimlerin tam desteğinin alınmasına ve hedeflenen çalışmaların ülke ulaşım politikalarına dahil edilmesine bağlıdır. Özel araç sahipliliğini destekleyen bir politika ile, özel araç sahipliliğini caydırıcı, motorlu taşıtların girişine izin vermeyen ya da toplu taşıma sistemi kullanımını başarıya ulaştıracak bir mekanizmadan söz edilemez. Dolayısıyla ülke politikalarının üst ölçekten alt ölçeğe kadar tutarlı olması, ulaşım güvenliğinin sağlanmasında yapılacak çalışmaların başarıya ulaşmasında anahtar role sahiptir. Tartışmaya açılan değişkenlerin test edilememiş olması, bu çalışmanın gelişime açı yönünü oluşturmaktadır. 


\title{
Extended Abstract
}

\section{Planning as a Tool for Providing Transportation Safety \\ *}

\author{
İrem Ayhan Selçuk \\ Dokuz Eylül University
}

As being a multi-tiered structure with its different types of land use, structure and population density, historical layers, transportation and infrastructure elements; "city" is a platform, strenghtening communication channels between people who has got different demographic, social and cultural classes and helping to transfer knowledge between culture to culture and ages to ages.

Having so many differences; resulting in a wide variety of incompatibilities in the city. The role of minimising these incompatibilites is under the responsibility of local manicupalities and experts working with them. Success of local government connects to find good solutions with understanding city space and its users.

City planning studies is a tool which can be use effectively for application of reducing traffic accidents. With the support of manucipalities; city planning has the steering power to the city or city zone with spatial decisions such as allowed vehicle types. So, spatial planning can be a tool for reducing traffic crime.

Problem of this sudy is the lackness of satisfactory analysis and synthes studies about spatial planning tools for providing transportation and traffic security and lackness of satisfactory reflections to the planning decisions on the aspect of urban safety.

The aim of this study is; supporting researchers for realizing scientific projects about testing spatial planning tools statistically for providing transportation safety; by suggesting and discussing present or new spatial planning tools. At the end of these process; people may have opportunity to live more livable environments. Study method is discussing planning tools for solving problems which causes traffic accidents.

Success in transportation security depends on the full support of local and central managements and the inclusion of targeted studies in national idealkent @ Kent Araştırmaları Dergisi (Journal of Urban Studies) 
transport policies. These goals are defined by laws and regulations; with the help of planning tools.

In general, some of the data provided by literature reviews have features that can be solved by means of the planning discipline. Some of them are related to different areas of expertise outside the study area of the planning discipline.

In this study, factors that could create danger in terms of transportation safety in the city were tried to be conveyed; what can be done to solve security problems is discussed by putting the planning as a tool.

Although transportation safety is considered more human-sourced; it can be considered that the correct design of the space will minimize many security problems. Therefore, establishing a resource to guide the expertises concerned with the design of the space is having great importance in terms of ensuring the safety of transportation.

If necessary to elaborate; tools to be tested and developed for transportation safety are; (1) net and gross population density decisions, (2) planned land use types, (3) frequent intersections / intersection points depending on the length of the structure, (4) road material, speed column, angle of the road line (suggestions for reducing the traffic speed of the lock parquet, etc.), (5) in terms of creating inhabited spaces (transit type / transit stop / population density crossing), (6) traffic speed, (7) refuge planting, (8) insufficient lighting, (9) dead-end streets, (10) sloping roads, (11) parking problems for every kind of vehicles, (12) old, pregnant, child, handicapped etc. the safety of other groups, (13) types of transportation and their relations with each other, (14) emergency vehicles and road features, (15) in terms of health problems (air pollution due to fuel type, noise pollution, noise and ground borne vibration), (16) road widths, (17) maintanence of road material, (18) one way applications, (19) public transport and their stops, (20) pedestrian and vehicle underpasses and overpasses, (21) traffic police spots and deterrent factors.

To have generalize; the studies carried out in the literature can be grouped under certain headings. These are; (1) studies related to traffic accidents and land use type (Songpatanasilp vd. (2015), Kundakçı (2014), Hashimoto (2005)), (2) studies that reveal the relationship between traffic accidents and population density (Hashimoto (2005), Autubi (2012)), (3) studies focusing on traffic accident analysis methods (Kundakçı (2014), Erdoğan vd. (2008), Yalçın (2015), Fenta ve Workie (2014), Selvasofia ve Arulraj (2016), Songpatanasilp vd. (2015), Shafabakhsh vd. (2017)), (4) studies related to traffic accidents and urban macroform (Shafabakhsh vd. 
(2017)), (5) studies focusing on the relationship between traffic accidents and road design (Çepni ve Arslan (2017), Selvasofia ve Arulraj'ın (2016), Songpatanasilp vd., (2015), Kundakçı (2014), Hashimoto, (2005)), (6) studies related to traffic accidents, traffic police control points and traffic police performance (Autubi (2012), Fenta ve Workie (2014)), (7) studies related to traffic accidents and safety of transportation (Polzin (b.t.), Shafabakhsh vd. (2017)), (8) studies investigating traffic accidents and realization times of traffic accidents (Folkard (1997), Ghosh, Parida ve Uraon (2004)), (9) studies claim that they constitute a large part of the transportation costs of safety (Savage (2013)), (10) pedestrian and vehicle-focused studies of traffic accidents (Yalçın (2015)), (11) studies analyzing traffic accidents and vehicle type relationship (Ghosh, Parida ve Uraon (2004)).

However, many planning tools that can be used in addition to these studies are also variables to be considered. Apart from land use types and population densities mentioned in the literature, the most important variables that can be used as a planning tool are; towing distances, pavement and road widths.

In terms of planning scales, this issue seems to be mostly application development plan scale and lower scales; when it is considered in terms of the transportation policies adopted, it is seen that the upper scale is also the topic.

Although planning legislation can be used for transportation and transportation safety, it has not yet been found to work as a guide on how it can be used to reduce transport safety. The number of studies with atypical spatial variables that are the guiding tasks to reduce traffic accidents is extremely small.

As mentioned before, success in transportation security; depends on the full support of local and central managements and the inclusion of targeted studies in national transport policies.

With a policy that supports private vehicle ownership, can not be said to be a mechanism that does not allow the entry of motor vehicles, or that will lead to the success of the use of public transport systems as a deterrent to private vehicle ownership. Therefore, the fact that the policies of the country are consistent from the upper scale to the lower scale, has a key role in the success of the work to be done in the provision of transportation safety. The fact that; the debate variables can not be tested constitutes; is the clear direction of the development of this work. 


\section{Kaynakça/References}

Autubi, A. O. (2012). Determinants of road traffic accident occurrences in Lagos state: Some lessons for Nigeria. International Journal of Humanities and Social Science, 2 (6), 252-259. 21 Ağustos 2017 tarihinde http://www.ijhssnet.com/journals/Vol_2_No_6_Special_Issue_March_2012/23.pdf adresinden erişildi.

Ayhan Selçuk, I., ve Çubukçu, K. M. (2013). Tarihi yapıların korunmasında ve koruma amaçlı imar planlarının hazırlanmasında bir belirleyici olarak trafik kaynaklı titreşimlerin ölçülmesi ve modellenmesi. (Doktora Tezi). http://www.fbe.deu.edu.tr/ALL_FILES/Tez_Arsivi/2013/dr_t843.pdf

Ayhan, İ., ve Çubukçu, K. M. (2007). Kentte suç oranının ekonomik, sosyal ve mekansal değişkenlerle modellenmesi. (Yüksek Lisans Tezi). http://www.fbe.deu.edu.tr/ALL_FILES/Tez_Arsivi/2007/yl_t2242.pdf

Çepni, M. S. ve Arslan, O. (2017). A gis approach to evaluate infrastructure variables influencing the occurence of traffic accidents in urban roads. Internatonal Journal of Environment and Geoinformatics (IJEGEO), 4 (1), 17-24. 27 Ağustos 2017 tarihinde http://ijegeo.org/wp-content/uploads/2017/01/IJEGEO_413.pdf adresinden erişildi.

Erdoğan, S., Yılmaz, İ., Baybura, T. ve Güllü, M. (2008). Geographical information systems aided traffic accident analysis system case study: City of Afyonkarahisar. Accident Analysis and Prevention, 40, 174-181. 26 Ağustos 2017 tarihinde https://www.researchgate.net/publication/5635281_Geographical_information_systems_aided_traffic_accident_analysis_system_case_study_City_of_Afyonkarahisar adresinden erișildi.

Fenta, H. M., \& Workie, D. L. (2014). Analysis of factors that affect road traffic accidents in Bahir Dar City, North Western Ethiophia. Science Journal of Applied Mathematics and Statistics, 2 (5), 91-96, doi: 10.11648/j.sjams.20140205.11

Folkard, S. (1997). Black Times: Temporal determinants of transport safety. Accid. Anal. And Prev., 29, (4), 417-430. 20 Ağustos 2017 tarihinde http://www.academia.edu/30626609/Black_times_Temporal_determinants_of_transport_safety adresinden erişildi.

Ghosh, S. K., Parida, M. ve Uraon, J. K. (2004). Traffic accident analysis for Dehradun City using gis. ITPI (Institute of Town Planners India) Journal, 1:3, 40-54. 27 Ağustos $2017 \quad$ tarihinde http://citeseerx.ist.psu.edu/viewdoc/download?doi=10.1.1.526.9713\&rep=rep1\&type=pdf adresinden erişildi.

Hashimoto, T. (2005). Spatial analysis of pedestrian accidents. (Yüksek Lisans Tezi). http://scholarcommons.usf.edu/cgi/viewcontent.cgi?article=3919\&context=etd

Joewono, T. B. ve Kubota, H. (2006). Safety and security improvement in public transportation based on public perception in developing countries. IATSS (International Association of Trafic and Safety Sciences) Research, 30 (1), 86-100. 20 Ağustos 2017 tarihinde http://www.sciencedirect.com/science/article/pii/S038611121460159X adresinden erişildi.

Kundakç1, E. (2014). Identification of urban traffic accident hot spots and their characeristics by using gis. (Yüksek Lisans Tezi). http://etd.lib.metu.edu.tr/upload/12617016/index.pdf 
Mulkat, A., Y. (2015). Impact assessment of road traffic accidents on Nigerian economy. Quest Journal, Journal of Research in Humanities and Social Science, 3 (12), 8-16. 21 Ağustos 2017 tarihinde http:/questjournals.org/jrhss/papers/vol3-issue12/B3120816.pdf adresinden erişildi.

Polzin, S. E. (b.t.). Security considerations in transportation planning: a white paper. 26 Ağustos 2017 tarihinde https://www.planning.dot.gov/documents/SecurityPapers/SecurityConsiderations_Polzin.htm adresinden erişildi.

Savage, I. (2013). Reflections on the economics of transportation safety. Published in Research in Transportation Economics: The Economics of Transportation Safety, 43 (1), 18. 21 Ağustos 2017 tarihinde http://faculty.wcas.northwestern.edu/ ipsavage/437manuscript.pdf adresinden erişildi.

Selvasofia, A., SD. ve Arulraj, P., G. (2016). Accident and traffic analsis using gis. Biomedical Research, An International Journal of Medical Sciences. 27 Ağustos 2017 tarihinde http://www.biomedres.info/biomedical-research/accident-and-trafficanalysis-using-gis.html adresinden erişildi.

Shafabakhsh, G. A., Famili, A., Bahadori, M. S. (2017). GIS-based spatial analysis of urban traffic accidents: Case study in Mashhad, İran. Journal of Traffic and Transportation Engineering (English Edition), 4 (3), 290-299. 28 Ağustos 2017 tarihinde http://www.sciencedirect.com/science/article/pii/S2095756417301988 adresinden erişildi.

Songpatanasilp, P., Yamada, H., Horanont, T. ve Shibasaki, R. (2015). Traffic accidents risk analysis based on road and land use factors using glms and ero-inflamated models. CUPUM, 2015. 27 Ağustos 2017 tarihinde http://web.mit.edu/cron/project/CUPUM2015/proceedings/Content/modeling/320_songpatanasilp_h.pdf adresinden erişildi.

Yalçın, G. (2015). Kent içi trafik yönetimi için trafik kazalarının mekansal analizi. Uluslararası Hakemli Mühendislik ve Fen Bilimleri Dergisi, 2 (3), 1-17. 26 Ağustos 2017 tarihinde http://www.hmfdergisi.com/dergi//kent-ici-trafik-yonetimi-icin-trafik-kazalarinin-mekansal-analizi201504.pdf adresinden erişildi.

\section{İrem Ayhan Selçuk,}

Dr. Öğr. Üyesi, Dokuz Eylül Üniversitesi, Mimarlık Fakültesi, Şehir ve Bölge Planlama Bölümü'nde görev yapıyor. Ulaşım ve trafik planlaması, trafik kaynaklı titreşimler, ulaşım ve trafik güvenliği, korunması gerekli alanlarda ulaşım ve trafik planlaması ve planlamada sayısal yöntemler alanlarında uzman olan Ayhan Selçuk'un ilgi alanları ulaşım ve trafik analizleri ile sayısal yöntemlerin planlama sorunlarının çözümünde kullanımına yönelik incelemelerdir.

Dr., Dokuz Eylul University, the Faculty of Architecture, Department of City and Regional Planning. As an expert on the fields of Transportation and Traffic Planning, Traffic Induced Vibrations, Transportation and Traffic Security, Transportation and Traffic Planning at Conservation Areas, Statistical Methods in Planning. Ayhan Selçuk is interested in Traffic and transportation analysis and statistical methods for solving planning problems.

E-mail: ayhan.irem@gmail.com

\section{Kaynakça Bilgisi / Citation Information}

Selçuk, İ.A. (2018). Ulaşım Güvenliğini Sağlamada Bir Araç Olarak Planlama. IDEALKENT - Kent Araştırmaları Dergisi, 23, 134-159. 